\title{
Comano's (Trentino) thermal water interferes with the expression and secretion of vascular endothelial growth factor-A protein isoforms by cultured human psoriatic keratinocytes: A potential mechanism of its anti-psoriatic action
}

\author{
ANNA CHIARINI ${ }^{1}$, ILARIA DAL PRA ${ }^{1}$, RAFFAELLA PACCHIANA $^{1}$, LIA MENAPACE $^{1}$, \\ GIUSEPPE ZUMIANI $^{2}$, MAURO ZANONI ${ }^{3}$ and UBALDO ARMATO ${ }^{1}$ \\ ${ }^{1}$ Histology and Embryology Unit, Department of Biomedical and Surgical Sciences, \\ University of Verona Medical School, I-37134 Verona; ${ }^{2}$ Dermatology Operative Unit, \\ Saint Chiara Hospital, I-38100 Trento; ${ }^{3}$ Research Centre, Terme di Comano, Trentino, Italy
}

Received January 20, 2006; Accepted March 15, 2006

\begin{abstract}
Thermal balneotherapy with Comano spa's water (CW; Trentino, Italy) is used for psoriasis and other skin disorders but the mechanism(s) of action of this hypotonic water are unknown. Since skin psoriatic manifestations are thought to be angiogenesis-dependent, we assessed CW's effects on the expression and release of VEGF-A protein isoforms by cultured human lesional keratinocytes isolated from skin biopsies performed in 9 patients. Confluent, psoriatic keratinocytes were exposed for 11 days to DMEM, whose chemicals had been dissolved in either deionised water (DW-DMEM, controls) or CW (CW-DMEM, treated cells). As detected by Western immunoblotting (WB), incubation in CW-DMEM elicited, with respect to DW-DMEM, an increase in intracellular and/or cell-bound L-VEGF-A ${ }_{189}$ and L-VEGF-A 165 $48 \mathrm{kDa}$ protein isoforms with no concurrent change in $\mathrm{L}$ VEGF-A $_{121}$ and L-VEGF-A ${ }_{165} 45 \mathrm{kDa}$ proteins. Moreover, WB analysis of the secreted VEGF-A (sVEGF-A) proteins showed that the 20 and $15 \mathrm{kDa}$ bands corresponding to different VEGF-A isoforms were directly and remarkably reduced in keratinocyte-conditioned CW-DMEM vs. DW-DMEM. Thus, $\mathrm{CW}$ interferes with VEGF-A isoform expression and secretion
\end{abstract}

Correspondence to: Professor Ubaldo Armato, Histology and Embryology Unit, Department of Biomedical and Surgical Sciences, University of Verona Medical School, Strada Le Grazie 8, I-37134 Verona, Italy

E-mail: ubaldo.armato@univr.it

Abbreviations: CW, Comano's thermal water; DW, deionized water; HSPGs, heparan sulphate proteoglycans; IL, interleukin; VEGF-A, vascular endothelial growth factor-A; L-VEGF-A, large VEGF-A; sVEGF-A, secreted VEGF-A; WB, Western immunoblotting

Key words: psoriasis, human keratinocytes, vascular endothelial growth factor-A, cytokines, chemokines, Comano's thermal water by the psoriatic keratinocytes. These effects would reduce all VEGF-A-mediated angiogenic, vessel permeabilising, and chemotactic effects, thereby at least in part explaining the beneficial actions of $\mathrm{CW}$ balneotherapy on the clinical manifestations of psoriasis.

\section{Introduction}

Psoriasis, a chronic inflammatory dermatosis affecting approximately $2 \%$ of the Western population, is clinically marked by relapsing-remitting manifestations of well-defined, symmetrical erythematous plaques covered by scales. Although it has a genetic basis, the pathogenesis of psoriasis remains unclear. Currently, psoriasis is believed to be a $\mathrm{T}$ lymphocyte-driven disorder (1). However, at skin lesional sites, early prominent proliferation of a particular subset of endothelial cells lining the venous limbs of capillary plexuses in the upper dermal papillae leads to the formation of tortuous, dilated, inflamed, and hyper-permeable vessels (2,3). As these vascular changes precede the plaque's epidermal hyperplasia and dermal infiltration by inflammatory cells (i.e. neutrophils, T lymphocytes, monocytes) $(4,5)$, it has been surmised that psoriasis is an angioproliferative ailment depending upon the release of angiogenic molecules by the epidermis (6-11). Increased amounts of several angiogenic cytokines, including transforming growth factor- $\alpha$ (TGF- $\alpha)$, tumour necrosis factor- $\alpha$ (TNF- $\alpha)$, interleukin-1 (IL-1), IL-6, IL-20, amphiregulin, plateletderived endothelial cell growth factor/thymidine phosphorylase (TP), endothelial cell stimulating angiogenesis factor (ESAF), and VEGF-A are produced and secreted by the psoriatic keratinocytes $(9,12-19)$.

VEGF-A, the archetypal and best characterized member of a family of angiogenic growth factors $(20,21)$, acts both as an endothelial cell-specific growth factor and as a chief regulator of angiogenesis and vascular permeability in both physiologic and pathologic conditions (20-23). The human VEGF-A gene, placed on chromosome 6p21.3 (24), contains eight exons $(25,26)$. Alternative splicing of the primary mRNA transcript encoded by the $V E G F-A$ gene at the level of exons 6 and 7 
(25) produces several mature mRNAs that are translated into many protein splice variants, according to their amino acid numbers (once the signal sequence has been cleaved), VEGF-A $_{206}$, VEGF-A $_{189}$, VEGF-A $_{183}$, VEGF-A $_{165}$, VEGF-A $_{148}$, VEGF-A $A_{145}$, and VEGF-A $A_{121}$ (26-30). Such isoforms exhibit differing receptor affinities and heparin- and heparan sulphatebinding abilities (31), but the details of their distinctive biological functions remain to be elucidated (32). Most VEGF-Aproducing cells, keratinocytes included (33), preferentially express VEGF-A ${ }_{189}$, VEGF-A $_{165}$, and VEGF-A ${ }_{121}$ (34). Another isoform, VEGF- $\mathrm{A}_{183}$, is also widely expressed, but often confused with VEGF-A ${ }_{189}$ (30). Besides, all VEGF-A protein isoforms can be post-translationally modified through proteolysis by plasmin, thereby generating biologically active VEGF-A $_{110}$ (29). Tissue specific patterns of VEGF mRNA splicing were demonstrated in rats, but the operative mechanisms controlling each splice variant's expression are not understood (34). Recently, translational regulation of VEGF expression was demonstrated; in fact, the very long 5'untranslated region (5'-UTR) of VEGF-A mRNA contains two independent internal ribosome entry sites (IRES A and B) that regulate the activity of two different initiation codons, respectively; AUG 1039 and CUG 499. This alternative translation initiation process allows the synthesis of different VEGF-A protein precursors with higher molecular weight called large VEGF-A (L-VEGF) isoforms beside the VEGF-A protein isoforms with a lower molecular weight (35-37). The L-VEGF-A isoforms are the CUG-translated forms and bear an $\mathrm{NH}_{2}$-terminal extension of 206 amino acids that is missing in the AUG-translated forms. The L-VEGF-A isoforms have an exclusive intracellular localization, but can be cleaved into two polypeptides and the resulting $\mathrm{COOH}$-terminal products with the same apparent size as the AUG-translated forms are secreted from the cells just like the AUG-translated forms. Thus, active VEGF-A protein isoforms can be produced either by initiation at the AUG 1039 or through synthesis of LVEGF-A followed by cleavage of the $\mathrm{NH}_{2}$-terminal extension of 206 amino acids (35-37). Active VEGF-A protein isoforms are produced and secreted as covalently linked homodimers (38), which bind via specific residues coded by exons 3 and 4 to the high affinity tyrosine kinase receptors, VEGF-R1 (flt-1 kinase) and VEGF-R2 (KDR kinase in man, $f l k$ kinase in mouse). These receptors are expressed only by endothelial cells (39-42). Dimerization and activation of VEGF-R1 and VEGF-R2 and of the VEGF-R2/VEGF-A ${ }_{165}$ co-receptor, neuropilin-1 (43), by their ligands is essential for endothelial cell migration, proliferation, differentiation, and survival (44). The importance of the roles of VEGF-A, VEGF-R1, and VEGF-R2 is stressed by the fact that the knockout of each gene, even at single allele level, has lethal consequences due to a defective development of the cardiovascular system in the mouse embryo (45-48).

VEGF-A released from cultured epidermal keratinocytes acts as an effective mitogen in endothelial cells of human dermal microvessels (49). Most importantly, targeted overexpression of VEGF in mouse skin keratinocytes results in an inflammatory condition chronically exhibiting all the traits proper of human psoriasis $(50,51)$. In this model, VEGF-A blockage effectively reversed all the abnormalities observed (51). Being a pleiotropic cytokine/chemokine, VEGF i)
Table I. Components of Comano's water. ${ }^{\mathrm{a}}$

\begin{tabular}{ll}
\hline Ions & \multicolumn{1}{c}{$\mathrm{mM}$} \\
\hline Sodium & 0.182 \\
Potassium & 0.026 \\
Magnesium & 1.010 \\
Calcium & 2.440 \\
Bicarbonate & 6.340 \\
Chloride & 0.047 \\
Sulfuric acid & 0.144 \\
Silicon & 0.163 \\
Fluorine & 0.048 \\
Lithium & 0.0002 \\
Aluminum & 0.00246 \\
Manganese & 0.00064 \\
Iron & 0.0038 \\
Copper & 0.0017 \\
Zinc & 0.00143 \\
Strontium & 0.00605 \\
\hline
\end{tabular}

${ }^{a}$ This water is hypotonic as its dry residue amounts to only $190 \mathrm{mg} / \mathrm{l}$.

stimulates the expression of ICAM-1, VCAM-1, and E-selectin in human umbilical vein endothelial cells (HUVECs) via the activation of transcription factor NF-кB (52); ii) induces the expression of IL-8, a chemokine that powerfully modulates the transcapillary diapedesis of neutrophils (53); and iii) brings about the activation and chemotaxis of VEGF-R1-expressing monocytes $(54,55)$. Hence, VEGF-A may act as a significant causal agent in human psoriasis; a notion having considerable therapeutic implications. In fact, agents used for the topical treatment of psoriasis, such as calcipotriol (a vitamin D3 analogue), retinoids (tazarotene), and cyclosporin A, are able to interfere, amongst other things, with VEGF-A production and release by keratinocytes (56-58).

Comano (Trentino, Italy) spa's water (CW) is a thermal hypotonic water containing various electrolytes (Table I). The major dermatological diseases so far treated via $\mathrm{CW}$ balneotherapy are psoriasis and atopic dermatitis (59). Other dermatoses also cared for with $\mathrm{CW}$ include contact dermatitis, seborrhoeic dermatitis, lichen planus, and palmoplantar keratosis (56). Previous in vivo studies showed the effectiveness of CW balneotherapy in the treatment of psoriasis, since it both significantly lessened hyperkeratosis, acantosis, and dermal papillomatosis and improved skin hydration (56). It must be recalled here that the permeability barrier of normal epidermis is severely disturbed in psoriatic skin $(60,61)$, and that bathing in hypotonic salt solutions triggers anti-inflammatory effects in lesional skin sites (62). However, the mechanisms through which the clinical signs of psoriasis (and of the other above mentioned skin disorders) are improved by means of $\mathrm{CW}$ balneotherapy have not as yet been clarified. To further understand the mechanism(s) involved in the therapeutic effectiveness of CW in psoriasis, we elected to investigate how CW would affect VEGF-A protein isoform expression 
and secretion on the part of cultured human adult psoriatic keratinocytes. In this report, we will show that the exposure of such cells to $\mathrm{CW}$ used instead of deionised water (DW) to dissolve the constituents of the DMEM medium both shifts the protein isoform expression towards the tightly cellassociated L-VEGF-A 189 isoform and diminishes the secretion of soluble VEGF-A proteins into the medium. These findings are consistent with $\mathrm{CW}$ being endowed with a complex antiangiogenic and hence anti-psoriatic therapeutic potential.

\section{Materials and methods}

Culture of psoriatic keratinocytes. Psoriatic epidermal keratinocytes were isolated from skin biopsy samples taken from 9 patients. After rapidly reaching the laboratory, the biopsies were incubated at $4^{\circ} \mathrm{C}$ overnight in a dispase II solution $(0.25 \%$ w/v; Roche, Milan, Italy). Weak enzymatic digestion allowed the epidermis (as a single lamina) to easily detach from the underlying dermis and subcutaneous tissue. By incubation in a trypsin solution $(0.25 \% \mathrm{w} / \mathrm{v})$, the isolated thin epidermal sheet was carefully and swiftly fragmented. Trypsin's action was next inhibited by adding an excess of serum, and the suspension of isolated cells was soon spun down at $600 \mathrm{rpm}$ for $10 \mathrm{~min}$ at $4^{\circ} \mathrm{C}$. The supernatant was decanted, the pellet resuspended, and the living cells counted in a Neubauer chamber. Keratinocytes were next seeded into plastic flasks precoated with a feeder-layer of preirradiated 3T3-J2 cells. To expand the keratinocyte population, MCDB153:1 medium [consisting of three parts of Dulbecco's modified Eagle's medium (DMEM) and one part of F12 medium; Sigma-Aldrich, Milan, Italy] was used, to which fetal bovine serum (FBS; $10 \% \mathrm{v} / \mathrm{v}$; BioWhittaker Europe, Belgium), antibiotics (solution of penicillinstreptomycin $1 \% \mathrm{w} / \mathrm{v}$; BioWhittaker Europe), epidermal growth factor (EGF; $0.1 \mu \mathrm{g} / \mathrm{ml}$; PeproTech, UK), insulin (20 ng/ml; PeproTech), and hydrocortisone $(0.5 \mu \mathrm{g} / \mathrm{ml}$; PeproTech) were added. This medium was replaced every two days with fresh samples of the same medium. Human psoriatic keratinocytes proliferated rapidly starting from minute clusters and formed a single layer of small and highly adherent epithelial cells. They had a mitotic doubling time of approximately $48 \mathrm{~h}$.

Experimental protocol. Psoriatic keratinocytes were detached from the culture flasks by means of a mild trypsin treatment and next seeded at $100 \%$ confluence density into wells containing either DMEM medium, whose chemical constituents had been dissolved in DW (controls in DW-DMEM) or CWDMEM, in which DW had been substituted with CW. Between days 3 and 11 of exposure to either medium, the keratinocytes and the cell-conditioned media were sampled and their contents of VEGF-A protein isoforms were analysed by immunocytochemistry and Western immunoblotting (WB).

Immunocytochemistry. At chosen time points, psoriatic keratinocytes exposed to either DW- or CW-DMEM were fixed with absolute methanol at $-20^{\circ} \mathrm{C}$ for $10 \mathrm{~min}$, washed twice with PBS and permeabilised in $0.1 \%$ Triton X-100 at room temperature for $15 \mathrm{~min}$. Then the cells were washed with PBS-FBS (1\%) (Cambrex BioScience, Milan, Italy) at room temperature for $1 \mathrm{~h}$ and next incubated for $1 \mathrm{~h}$ at $37^{\circ} \mathrm{C}$ with a rabbit polyclonal anti-VEGF-A antibody (final dilution
$10 \mu \mathrm{g} \cdot \mathrm{ml}^{-1}$; Santa Cruz Biotechnology, Inc., Germany). Next, keratinocytes were washed three times with PBS-FBS (1\%) and incubated for $1 \mathrm{~h}$ at room temperature in the dark with a specific secondary antibody (1:100 dilution) conjugated with Alexa Fluor-488 (Molecular Probes, Invitrogen Corp., Carlsbad, CA). Control cells not exposed to the primary antibody were always run in parallel. The cells were finally examined under an LSM 510 confocal microscope (Carl Zeiss S.p.A., Milan, Italy).

Western immunoblotting (WB). WB was performed on cellular lysates and on dialysed samples of cell-conditioned growth media of either kind. Psoriatic keratinocytes were scraped into cold PBS and sedimented at $200 \mathrm{x}$ g for $10 \mathrm{~min}$. The sedimented cells were homogenized in T-PER ${ }^{\mathrm{TM}}$ tissue protein extraction reagent (Pierce Chemical Co., Rockford, IL) containing a complete EDTA-free protease inhibitor cocktail (Roche Diagnostics, Monza, Italy). The protein contents of the samples were assayed by Bradford's method (63) using bovine serum albumin as a standard. Equal amounts (10 or $20 \mu \mathrm{g}$ ) of proteins from each cell lysate or cell-conditioned DW- or CW-DMEM $(25 \mu \mathrm{l})$ were boiled in sample buffer (0.0625 M Tris-HCl, pH 6.8, 2\% w/v SDS, 5\% w/v ß-mercaptoethanol, $10 \% \mathrm{v} / \mathrm{v}$ glycerol, $0.002 \% \mathrm{w} / \mathrm{v}$ bromphenol blue) and electrophoresed in $10 \% \mathrm{w} / \mathrm{v}$ SDS-polyacrylamide gel. The separated proteins were blotted onto a nitrocellulose membrane (0.45 $\mu \mathrm{m}$; Bio-Rad Laboratories, Hercules, CA). To immunodetect VEGF-A protein isoforms, the blots were probed with a rabbit polyclonal antibody (final dilution $1.0 \mu \mathrm{g} \cdot \mathrm{ml}^{-1}$; Santa Cruz). Blots were next incubated with alkaline phosphatase-conjugated anti-rabbit IgG (Santa Cruz), and stained with BCIP/NBT liquid substrate reagent (Sigma). Developed blots were photographed with an Olympus $3300^{\mathrm{TM}}$ digital camera, and the determination of the $\mathrm{M}_{\mathrm{r}}$ and the densitometric analysis of each specific protein band were carried out using Sigmagel $^{\mathrm{TM}}$ software (Jandel Corp., Erkrath, Germany).

Statistical analysis. One-way analysis of variance (ANOVA) with post hoc Bonferroni test was used to compare mean values and a significance level of 0.05 was chosen.

\section{Results}

Immunocytochemistry. An antibody recognizing the 189, 165 , and 121 amino acid protein isoforms of VEGF-A known to be expressed by human keratinocytes (33) decorated subcellular cytoplasmic, but not nuclear, structures of all the human psoriatic keratinocytes cultured for up to 11 days in either DW-DMEM or CW-DMEM. Notably, the intracellular or cell-bound amount of the fluorescent material decreased with time in the DW-DMEM-incubated (control) cells, whereas it increased with time in the CW-DMEM-exposed (treated) keratinocytes (Fig. 1).

Effects of exposure to DW-DMEM or CW-DMEM on intracellular and/or cell-bound VEGF-A protein isoforms. WB analysis under reducing conditions showed that total proteins extracted from cultured human psoriatic keratinocytes kept in either DW-DMEM or CW-DMEM contained L-VEGF-A 121 (35 kDa), L-VEGF-A 165 (45 and $48 \mathrm{kDa}$ bands due to different 


\section{VEGF-A}

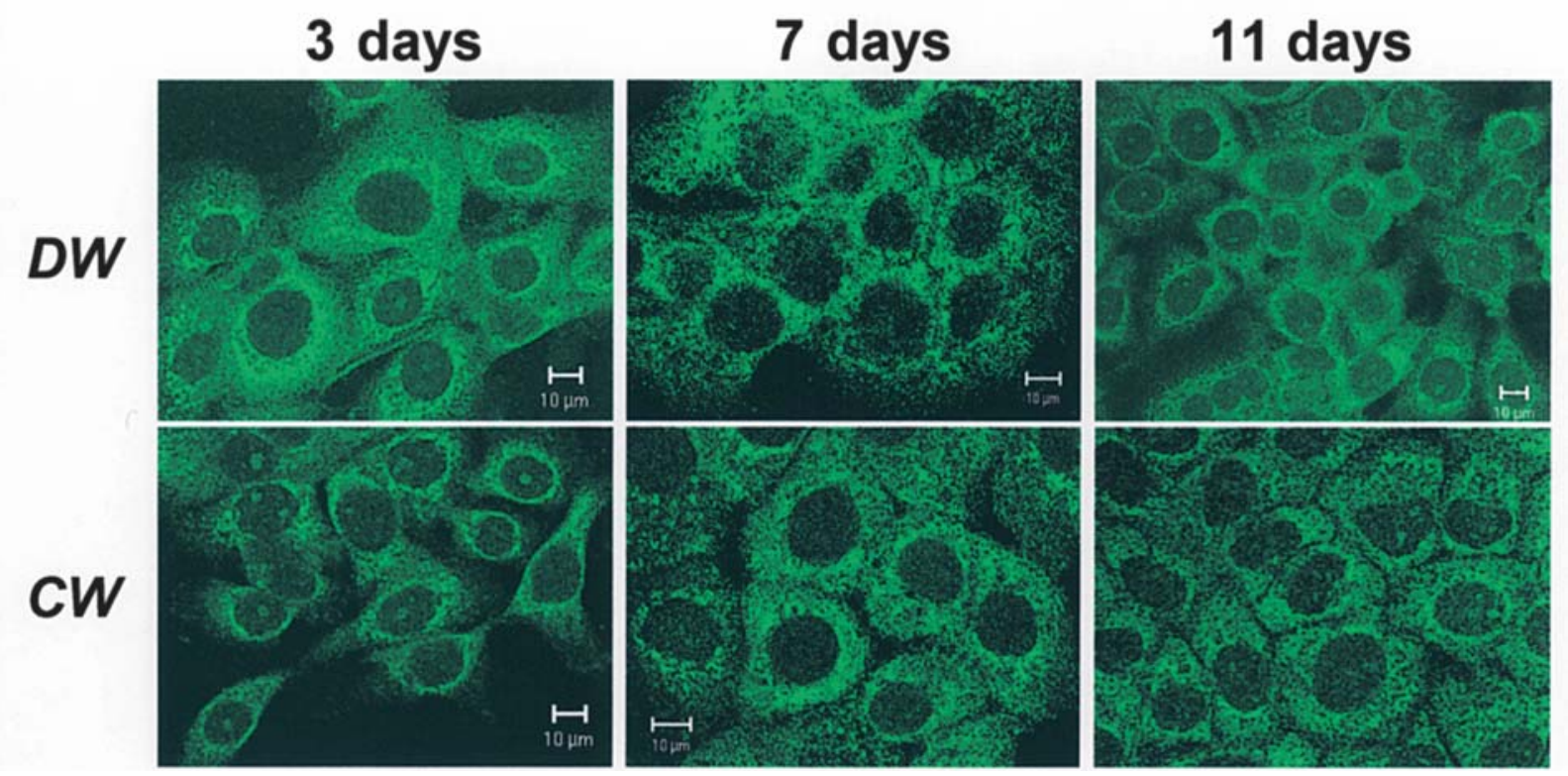

Figure 1. Intracellular and/or cell-bound VEGF-A proteins were down-regulated with time in human psoriatic keratinocytes cultured in DW-DMEM (controls), whereas they were up-regulated when the same cells were incubated in CW-DMEM. After 3, 7 and 11 days in vitro, the cells were processed for immunocytochemistry with an anti-VEGF-A antibody (for details see Materials and methods). The pictures shown are representative of 9 experiments.

glycosylation levels), and L-VEGF-A ${ }_{189}(55 \mathrm{kDa})$ isoforms (Fig. 2A) (35-37,64). The densitometric analysis of the specific bands showed that, in cells exposed to both media, the amounts of L-VEGF-A $\mathrm{A}_{189}$, the most intensely expressed isoform, and VEGF-A $_{165} 48 \mathrm{kDa}$ underwent significant time-related changes (Fig. 2B and C). In fact, L-VEGF-A ${ }_{189} 48 \mathrm{kDa}$ levels at day 3 were 4-fold higher $(\mathrm{p}<0.001)$ in control (DW-DMEM) than in treated (CW-DMEM) keratinocytes, but the opposite was true 8 days later, when L-VEGF-A ${ }_{189}$ levels had fallen to onefourth of their starting values in DW-DMEM-kept (control) cells, yet had increased more than 4-fold in CW-DMEMexposed (treated) keratinocytes $(\mathrm{p}<0.001$ vs. day 3 values in either instance) (Fig. 2B). Though being identical at day 3, VEGF-A $A_{165} 48 \mathrm{kDa}$ levels fell significantly in the keratinocytes grown in DW-DMEM, while increasing in the cells kept in CW-DMEM (Fig. 2C). Evaluating the areas under the respective curves made it clear that, between days 3 and 11, the total intracellular and/or cell-bound levels of L-VEGF-A ${ }_{189}$ and VEGF-A ${ }_{165} 48 \mathrm{kDa}$ were greater in CW-DMEM-incubated than in DW-DMEM-exposed keratinocytes (Fig. 3A).

Concurrently, the point by point and total intracellular or cell-bound levels of L-VEGF-A ${ }_{165} 45 \mathrm{kDa}$ and L-VEGF-A 121 did not significantly change and did not differ between keratinocytes kept either in DW-DMEM or in CW-DMEM (Fig. 2D and E, Fig. 3A).

Effects of exposure to DW-DMEM or to CW-DMEM on secreted VEGF-A (sVEGF-A) proteins. To assess whether the exposure to CW-DMEM changed the secretion pattern of VEGF-A proteins, the dyalised protein fractions of keratinocyte-conditioned growth media of both kinds were analysed by WB under reducing conditions. In keeping with the findings of
Ballaun et al (33), three sVEGF-A monomeric protein bands of 15,20 , and $24 \mathrm{kDa}$ respectively were detected in either group of samples. As VEGF-A ${ }_{189}$ isoform is known to remain cell-associated (65), the three bands thus detected are likely to correspond to differentially glycosylated VEGF-A 165 and VEGF-A $A_{121}$ isoforms $(33,66,67)$. These bands were subjected to densitometric analysis (Fig. 4).

The sVEGF-A $24 \mathrm{kDa}$ band was the thickest one in either DW- or CW-DMEM, keratinocyte-conditioned media, in both of which, excepting at day 11, it behaved similarly (Fig. 4A and B). There occurred a peak of sVEGF-A $24 \mathrm{kDa}$ protein at day 5 (a 2-fold increase over starting levels: $\mathrm{p}<0.001$ ), followed by a rapid drop to approximately one-third of the initial level at day 7 ( $\mathrm{p}<0.001$ in either instance vs. day 3 values) in both kinds of medium. But, at day 11, the amount of sVEGF-A $24 \mathrm{kDa}$ protein was significantly lesser (-31\%, $\mathrm{p}<0.05$ ) in CW-DMEM than in DW-DMEM samples (Fig. 4B). However, since this decrease was small and delayed, the total amount of sVEGF-A $24 \mathrm{kDa}$ protein, as assessed by evaluating the areas under the respective curves, did not significantly differ in relation to the type of growth medium considered (Fig. 3B).

The sVEGF-A 20-kDa protein was the second most abundant one secreted into either DW- or CW-DMEM, but its behaviour clearly differed according to the type of medium used (Fig. 4A and C). In DW-DMEM (controls), sVEGF-A $20-\mathrm{kDa}$ protein levels peaked at day 5 (at approximately twice that of starting levels: $\mathrm{p}<0.001)$, but rapidly fell to approximately half of its opening values $(\mathrm{p}<0.001)$ at days 7 and 11 (Fig. 4C). However, in CW-DMEM (treated cells), sVEGF-A $20-\mathrm{kDa}$ protein levels at day 3 were much lower $(-60 \%$, $\mathrm{p}<0.001$ ) than in DW-DMEM (Fig. 4C). Moreover, sVEGF-A $20-\mathrm{kDa}$ protein levels were also lower at day $5(-68 \%, \mathrm{p}<0.001)$ 


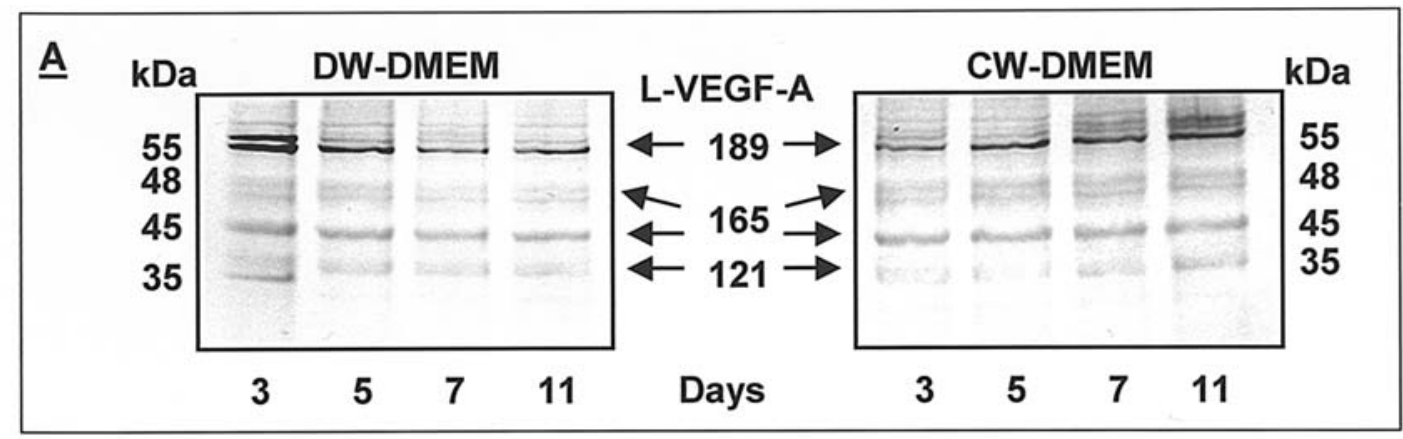

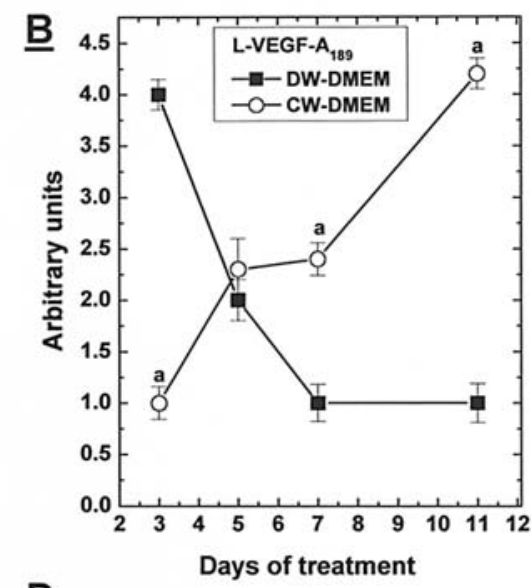

$\underline{\mathrm{D}}$

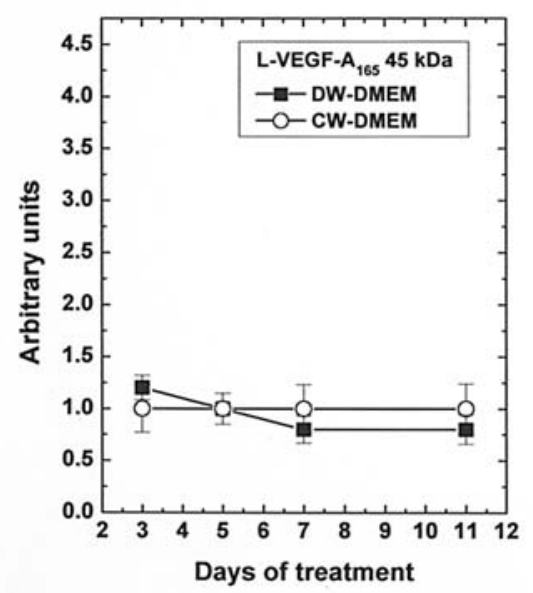

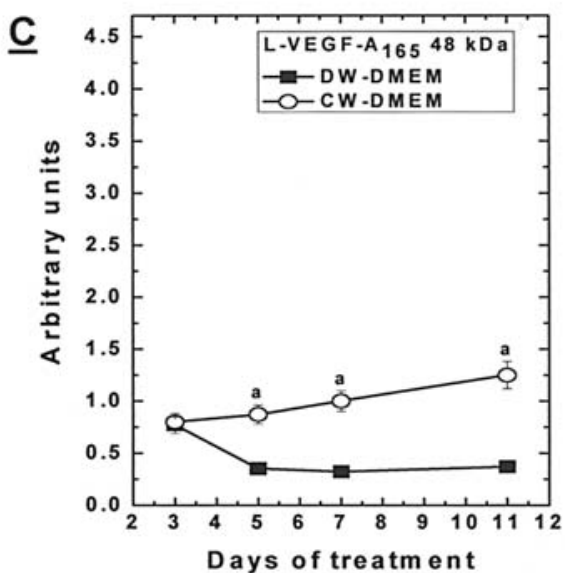

$\underline{E}$

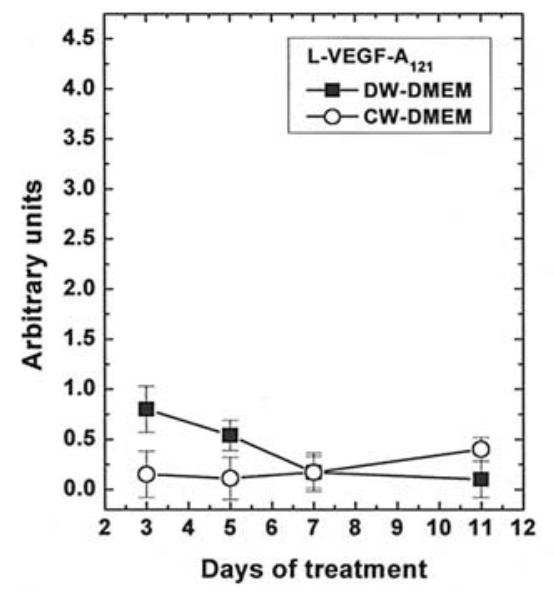

Figure 2. CW up-regulates the levels of intracellular and/or cell-bound L-VEGF-A ${ }_{189}$ and L-VEGF- $\mathrm{A}_{165}$ 48-kDa protein isoforms without affecting the intracellular and/or cell-bound levels of L-VEGF-A $16545 \mathrm{kDa}$ and L-VEGF-A ${ }_{121}$ in cultured human adult psoriatic keratinocytes. (A) Immunoblots were prepared from the protein extracts of psoriatic keratinocytes incubated in either CW-DMEM or DW-DMEM and sampled at devised time points. For technical details, consult the Materials and methods. The blots shown are representative of 9 experiments. (B-E) Densitometric analyses of the specific protein bands corresponding to each LVEGF-A isoform detected in the protein extracts from psoriatic keratinocytes incubated in either CW-DMEM or DW-DMEM samples. Points on the curves are means \pm SEM of 9 distinct experiments. Levels of statistical significance vs. corresponding DW-DMEM (controls) values: ${ }^{a} \mathrm{p}<0.001$.

vs. corresponding DW-DMEM levels and kept falling (at day $11,-55 \%, \mathrm{p}<0.001$ vs. DW-DMEM values) (Fig. 4C). Thus, with respect to DW-DMEM medium, the amount of sVEGF-A 20-kDa protein in CW-DMEM was severely reduced and, between days 3 and 11, was significantly less $(-56.4 \%, \mathrm{p}<0.001)$ than in DW-DMEM samples (Fig. 3B).

The sVEGF-A $15-\mathrm{kDa}$ protein was the least abundant one secreted into either DW-DMEM or CW-DMEM and, just like the sVEGF-A 20-kDa protein, behaved quite differently according to the kind of growth medium employed. In DWDMEM (controls), sVEGF-A 15-kDa protein peaked at day 5 (a 3-fold surge over starting values: $\mathrm{p}<0.001$ ) to fall between days 7 and 9 to levels slightly higher than the initial ones (Fig. 4D). However, in CW-DMEM, sVEGF-A 15-kDa protein levels were lower from the outset than in the alternative medium and remained such up to day 11 (e.g., $-70 \%, \mathrm{p}<0.001$ at day 5) (Fig. 4D). Thus, the total amount of sVEGF-A 15-kDa protein released between days 3 and 11 into the CW-DMEM 


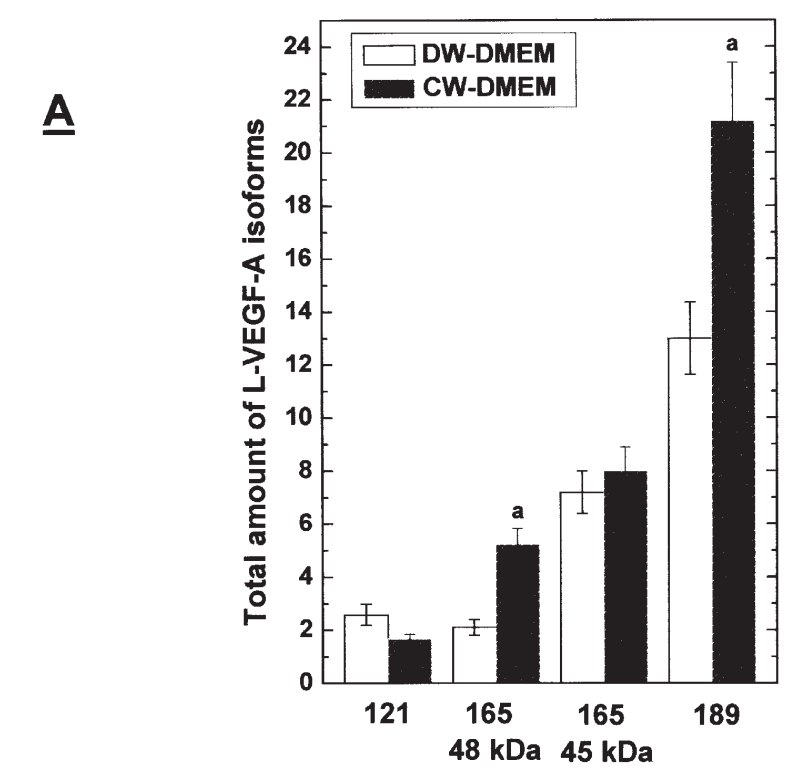

$\underline{B}$

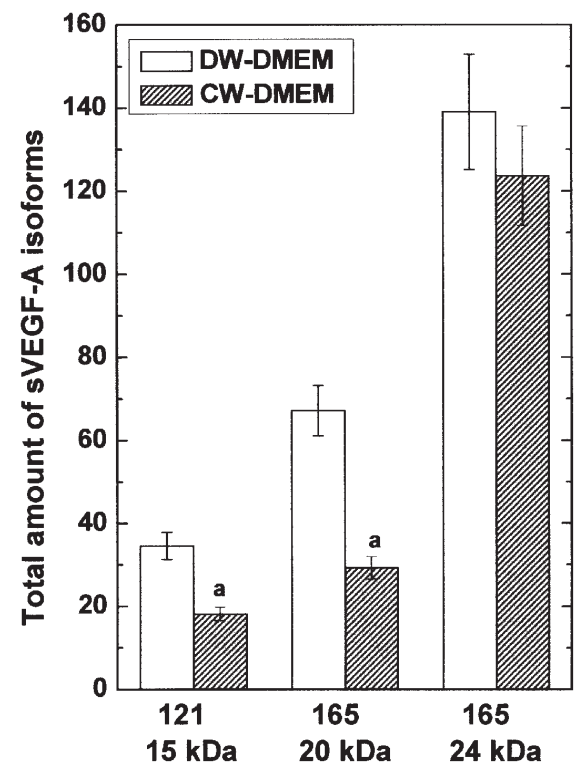

Figure 3. Incubation in CW-DMEM up-regulates the total (3-11 days) intracellular and/or cell-bound expression of L-VEGF- $\mathrm{A}_{189}$ and L-VEGF- $\mathrm{A}_{165}$ 48-kDa isoforms (A), while curtailing the total (3-11 days) secretion of the 20- and 15-kDa sVEGF-A proteins likely to pertain to differently glycosylated VEGF- $\mathrm{A}_{165}$ and VEGF-A $\mathrm{A}_{121}$ proteins (33) (B). Total values were obtained by evaluating the areas under the corresponding curves of Fig. 2B-E and Fig. 4B-D. Levels of statistical significance vs. corresponding DW-DMEM values: ${ }^{\mathrm{a}} \mathrm{p}<0.001$.

was approximately half $(\mathrm{p}<0.001)$ of that released into the DW-DMEM (Fig. 4B). No band with $\mathrm{M}_{\mathrm{r}}$ lower than $15 \mathrm{kDa}$, which would have corresponded to sVEGF-A $\mathrm{A}_{110}$, was detected in any of the medium samples examined.

\section{Discussion}

VEGF fits in the dimeric cysteine-knot growth factor superfamily (68). VEGF-A-producing cells, keratinocytes included, simultaneously express several VEGF-A protein isoforms, amongst which VEGF-A $\mathrm{A}_{121}$ and VEGF-A ${ }_{165}$ appear to predominate in normal tissues $(26,33)$ and in psoriatic scales (67). According to the present findings, cultured human psoriatic keratinocytes express the same three isoforms, i.e. L-VEGF$\mathrm{A}_{189}$, L-VEGF- $\mathrm{A}_{165}$, and L-VEGF- $\mathrm{A}_{121}$, while secerning active though differently glycosylated VEGF- $\mathrm{A}_{165}$, and VEGF- $\mathrm{A}_{121}$, as normal keratinocytes do (33).

VEGF- $A_{189}$ retains sequences encoded by both exons 6 and 7 (26), and its binding affinity for heparin and heparan sulphates is higher than that of VEGF-A $\mathrm{A}_{165}$ or VEGF-A $\mathrm{A}_{145}(69)$. Because of such an affinity, secreted VEGF- $\mathrm{A}_{189}$ is sequestered on heparan sulphate proteoglycans (HSPGs) at the cell surface and thus remains tightly associated to the producing cells $(65,69)$. Moreover, VEGF- $\mathrm{A}_{189}$ is a much less effective angiogenic factor than either VEGF-A $\mathrm{A}_{165}$ or VEGF-A $\mathrm{A}_{121}$ (70) even because VEGF-A $\mathrm{A}_{189}$ receptor-binding sequences are masked when the protein is normally folded. In fact, recombinant VEGF-A $A_{189}$ cannot bind VEGF-R2 receptor and is thereby unable to directly stimulate endothelial cell growth (31). To mature and become able to bind VEGF-R2 and act as an endothelial cell mitogen, secreted VEGF- $\mathrm{A}_{189}$ must be extracellularly cleaved by urokinase-type plasminogen activator (uPA) or plasmin into VEGF-A $110(65,71)$. However, no 110 amino acid sVEGF-A isoform was released into the growth media conditioned by human normal or psoriatic keratinocytes (33, and present findings).

Our immunocytochemistry and WB findings show that a protracted incubation in CW-DMEM causes a slow yet progressive intracellular and/or cell-bound accumulation of both L-VEGF-A $\mathrm{A}_{189}$ and L-VEGF-A ${ }_{165} 48-\mathrm{kDa}$ isoforms. It should be noticed that, in quantitative terms, the expression of L-VEGF-A ${ }_{189}$ by the psoriatic keratinocytes is at least 4-fold greater than that of L-VEGF-A ${ }_{165} 48 \mathrm{kDa}$ (Fig. 2B and C, Fig. 3A). Hence, the exposure to $\mathrm{CW}$ is likely to favour, by mechanisms at present not understood, the mRNA alternative splicing leading to the synthesis of L-VEGF- $\mathrm{A}_{189}$ and possibly of the highly glycosylated L-VEGF- $\mathrm{A}_{165} 48-\mathrm{kDa}$ isoform. By itself, this increased expression of tightly keratinocyte-bound VEGF-A ${ }_{189}$ and VEGF-A ${ }_{165}$ (65) might result in a lesser direct stimulation of endothelial cell growth (31). Interestingly, a dynamic shift towards the expression of VEGF- $\mathrm{A}_{189}$ has been observed to occur in the human uterus under the effects of progesterone (72). It has been surmised that bound VEGF isoforms might provide a reserve of growth factor available in its biologically active forms, both as endothelial cell mitogens and vascular permeability-enhancing agents, however only after their effective cleavage by heparinase or uPA $(65,72)$.

VEGF- $\mathrm{A}_{165}$ isoform contains 15 basic amino acids encoded by exon 7 and its affinity for heparin is moderate $(31,71)$. VEGF- $\mathrm{A}_{165}$ is actively secreted by the producing cells and most of it (i.e. 50-70\%) associates with extracellular matrix (ECM) and cell surfaces due to its interactions with HSPGs (65). On the other hand, VEGF-A $A_{121}$ is a weakly acidic molecule as it is devoid of exon 7-encoded basic amino acids. Since it binds neither heparin (25) nor ECM (69), VEGF-A $A_{121}$ is soluble and rapidly released (65). Notably, VEGF-A $\mathrm{A}_{121}$ requires cell surface HPSGs to bind VEGF receptors (73) and, compared to VEGF- $\mathrm{A}_{165}$, is a weaker mitogen for the endothelial cells (71). Our findings show that, at variance with VEGF-A $\mathrm{A}_{189}$ and VEGF-A $16548 \mathrm{kDa}$, VEGF-A $A_{165} 45 \mathrm{kDa}$ and VEGF- $\mathrm{A}_{121}$ do not accumulate inside 


\section{sVEGF-A PROTEINS}
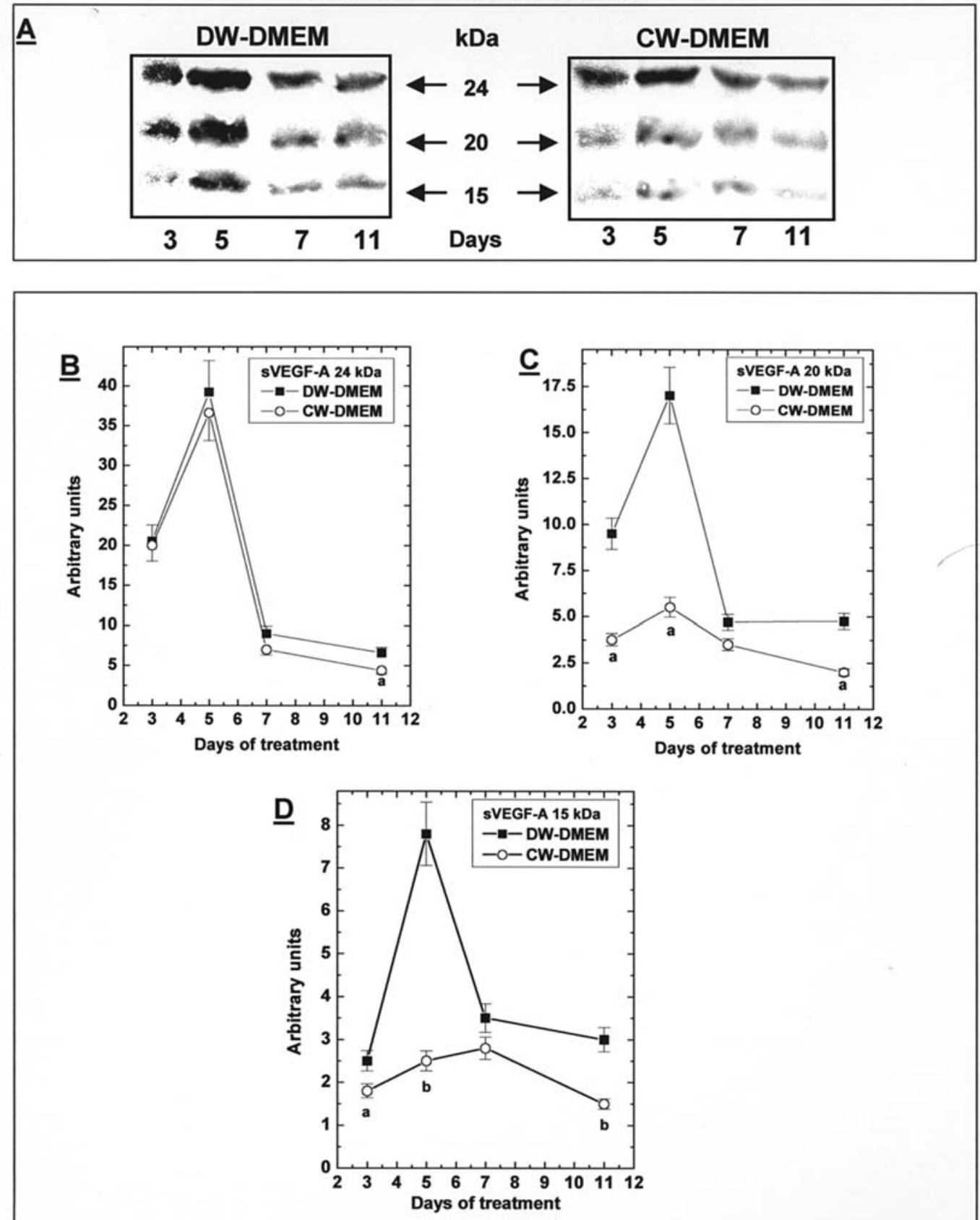

Figure 4. Incubation in CW-DMEM rapidly and markedly reduced the secretion of 20-kDa and 15-kDa sVEGF-A proteins likely to pertain to differently glycosylated VEGF- $A_{165}$ and VEGF-A $A_{121}$ isoforms (33). By contrast, 24-kDa sVEGF- $A_{165}$ protein starts decreasing significantly only by the 11 th day of exposure to CW-DMEM. (A) Immunoblots of the proteins extracted from keratinocyte-conditioned CW-DMEM or DW-DMEM media sampled at devised time points. Relative masses $\left(\mathrm{M}_{\mathrm{r}}\right)$ are indicated. The blots shown are representative of 9 experiments. (B-D) Densitometric analyses of the specific sVEGF-A protein bands secreted into keratinocyte-conditioned CW-DMEM or DW-DMEM samples. Points on the curves are means \pm SEM of 9 distinct experiments. Levels of statistical significance vs. corresponding DW-DMEM (controls) values; B and C, ${ }^{\mathrm{a}} \mathrm{p}<0.001 ; \mathrm{D},{ }^{\mathrm{a}} \mathrm{p}<0.01 ;{ }^{\mathrm{b}} \mathrm{p}<0.001$.

or remain attached to the surfaces of CW-DMEM-incubated psoriatic keratinocytes. Yet, with respect to the DW-DMEM, the release of differentially glycosylated 24-, 20-, and 15-kDa sVEGF-A proteins $(33,66,67)$ likely pertaining to differently glucosylated VEGF-A $A_{165}$ and VEGF-A $A_{121}$ isoforms (33) into the CW-DMEM is cut by more than half. Therefore, our results indicate that exposure to $\mathrm{CW}$ does not favour the synthesis and secretion of both VEGF-A $A_{165}$ and VEGF-A $A_{121}$ proteins. These effects would translate into a diminished direct angiogenic stimulation on the part of psoriatic keratinocytes (31).
Overall, the present results support the view that $\mathrm{CW}$ balneotherapy is likely to interfere at the level of psoriatic skin lesions, where the permeability barrier is seriously compromised $(60,61)$, with the protein synthesis and secretion of the three main VEGF-A protein isoforms expressed by the psoriatic keratinocytes. CW exposure would shift the balance in favour of the tightly cell-associated and by itself nonmitogenic (for the endothelial cells) L-VEGF-A ${ }_{189}$ and LVEGF-A ${ }_{165} 48-\mathrm{kDa}$ isoforms at the expense of the promptly secreted and direct endothelial cell mitogens, VEGF-A $\mathrm{A}_{165}$ and 
VEGF- $\mathrm{A}_{121}$ isoforms. Besides locally decreasing the intensity of angiogenic stimulation, CW also reduces i) VEGF-A-elicited alteration of vascular permeability (4); ii) the expression of the neutrophil chemokine, IL-8 (53); iii) VEGF-A's own chemotactic effects on monocytes $(54,55,74)$; and iv) the expression of ICAM-1, VCAM-1, and E-selectin in human endothelial cells (52).

Further lines of evidence that we are presently gathering show that in vitro exposure to CW-DMEM also interferes with the increased expression and secretion of at least two more angiogenic cytokines, IL-1 and IL-6 (9,12-19), on the part of human psoriatic keratinocytes (unpublished data). Conceivably, such complex anti-angiogenic effects brought about by CW balneotherapy would justify, from a pathophysiological standpoint, at least part of its known beneficial effects on the clinical manifestations of psoriasis (59), and concurrently rule out the possibility that such benefits are of the placebo kind.

\section{References}

1. Bos JD and De Rie MA: The pathogenesis of psoriasis. Immunol Today 20: 40-46, 1999.

2. Telner $P$ and Fekete Z: The capillary responses in psoriatic skin. J Invest Dermatol 36: 225-230, 1961.

3. Creamer D, Allen MH, Sousa A, Poston R and Barker JN: Localization of endothelial proliferation and microvascular expansion in active plaque psoriasis. Br J Dermatol 136: 859-865, 1997.

4. Braverman IM and Sibley J: Role of the microcirculation in the treatment and pathogenesis of psoriasis. J Invest Dermatol 78: 12-17, 1982.

5. Schubert $\mathrm{C}$ and Christophers E: Mast cells and macrophages in early relapsing psoriasis. Arch Dermatol Res 277: 352-358, 1985.

6. Folkman J: Angiogenesis in psoriasis: therapeutic implications. J Invest Dermatol 59: 40-43, 1972.

7. Barker JN: The pathophysiology of psoriasis. Lancet 338 : 227-230, 1991.

8. Goodfield M, Hull SM, Holland D, Roberts G, Wood E, Reid S and Cunliffe W: Investigations of the 'active' edge of plaque psoriasis: vascular proliferation precedes changes in epidermal keratin. Br J Dermatol 131: 808-813, 1994.

9. Creamer D, Sullivan D, Bicknell R and Barker J: Angiogenesis in psoriasis. Angiogenesis 5: 231-236, 2002.

10. Malhotra R, Stenn KS, Fernandez LA and Braverman IM: Angiogenic properties of normal and psoriatic skin associate with epidermis, not dermis. Lab Invest 61: 162-165, 1989.

11. Barnhill RL, Parkinson EK and Ryan TJ: Supernatants from cultured human epidermal keratinocytes stimulate angiogenesis. Br J Dermatol 110: 273-281, 1984.

12. Nickoloff BJ, Mitra RS, Varani J, Dixit VM and Polverini PJ: Aberrant production of interleukin- 8 and thrombospondin- 1 by psoriatic keratinocytes mediates angiogenesis. Am J Pathol 144: 820-828, 1994.

13. Ettehadi P, Greaves MW, Wallach D, Aderka D and Camp RD: Elevated tumour necrosis factor-alpha (TNF-alpha) biological activity in psoriatic skin lesions. Clin Exp Immunol 96: 146-151, 1994.

14. Elder JT, Fisher GJ, Lindquist PB, Bennett GL, Pittelkow MR, Coffey RJ Jr, Ellingsworth L, Derynck R and Voorhees JJ: Overexpression of transforming growth factor alpha in psoriatic epidermis. Science 243: 811-814, 1989.

15. Creamer D, Jaggar R, Allen M, Bicknell R and Barker J: Overexpression of the angiogenic factor platelet-derived endothelial cell growth factor/thymidine phosphorylase in psoriatic epidermis. Br J Dermatol 137: 851-855, 1997.

16. Bonifati $\mathrm{C}$ and Ameglio F: Cytokines in psoriasis. Int J Dermatol 38: 241-251, 1999.

17. Blumberg H, Conklin D, Xu WF, et al: Interleukin 20: discovery, receptor identification, and role in epidermal function. Cell 104: 9-19, 2001.
18. Detmar M, Brown LF, Claffey KP, Yeo KT, Kocher O, Jackman RW, Berse B and Dvorak HF: Overexpression of vascular permeability factor/vascular endothelial growth factor and its receptors in psoriasis. J Exp Med 180: 1141-1146, 1994.

19. Bhushan M, McLaughlin B, Weiss JB and Griffiths CE: Levels of endothelial cell stimulating angiogenesis factor and vascular endothelial growth factor are elevated in psoriasis. Br J Dermatol 141: 1054-1060, 1999.

20. Gimbrone MA Jr, Obin MS, Brock AF, et al: Endothelial interleukin-8: a novel inhibitor of leukocyte-endothelial interactions. Science 246: 1601-1603, 1989.

21. Thomas KA: Vascular endothelial growth factor, a potent and selective angiogenic agent. J Biol Chem 271: 603-606, 1996.

22. Ferrara N: VEGF and the quest for tumour angiogenesis factors. Nat Rev Cancer 2: 795-803, 2002.

23. Keck PJ, Hauser SD, Krivi G, Sanzo K, Warren T, Feder J and Connolly DT: Vascular permeability factor, an endothelial cell mitogen related to PDGF. Science 246: 1309-1312, 1989.

24. Vincenti V, Cassano C, Rocchi M and Persico G: Assignment of the vascular endothelial growth factor gene to human chromosome 6p21.3. Circulation 93: 1493-1495, 1996.

25. Tischer E, Mitchell R, Hartman T, Silva M, Gospodarowicz D, Fiddes JC and Abraham JA: The human gene for vascular endothelial growth factor. Multiple protein forms are encoded through alternative exon splicing. J Biol Chem 266: 11947-11954, 1991.

26. Houck KA, Ferrara N, Winer J, Cachianes G, Li B and Leung DW: The vascular endothelial growth factor family: identification of a fourth molecular species and characterization of alternative splicing of RNA. Mol Endocrinol 5: 1806-1814, 1991.

27. Whittle C, Gillespie K, Harrison R, Mathieson PW and Harper SJ: Heterogeneous vascular endothelial growth factor (VEGF) isoform mRNA and receptor mRNA expression in human glomeruli, and the identification of VEGF148 mRNA, a novel truncated splice variant. Clin Sci 97: 303-312, 1999.

28. Poltorak Z, Cohen T, Sivan R, Kandelis Y, Spira G, Vlodavsky I, Keshet $\mathrm{E}$ and Neufeld G: $\mathrm{VEGF}_{145}$, a secreted vascular endothelial growth factor isoform that binds to extracellular matrix. J Biol Chem 272: 7151-7158, 1997

29. Keyt BA, Berleau LT, Nguyen HV, Chen H, Heinsohn H, Vandlen R and Ferrara N: The carboxyl-terminal domain (111-165) of vascular endothelial growth factor is critical for its mitogenic potency. J Biol Chem 271: 7788-7795, 1996.

30. Lei J, Jiang A and Pei D: Identification and characterization of a new splicing variant of vascular endothelial growth factor: VEGF $_{183}$. Biochim Biophys Acta 1443: 400-406, 1998.

31. Neufeld G, Cohen T, Gengrinovitch S and Poltorak Z: Vascular endothelial growth factor (VEGF) and its receptors. FASEB J 13: 9-22, 1999.

32. Kroupis C, Stathopoulou A, Zygalaki E, Ferekidou L, Talieri M and Lianidou ES: Development and applications of a real-time quantitative RT-PCR method (QRT-PCR) for BRCA1 mRNA. Clin Biochem 38: 50-57, 2005.

33. Ballaun C, Weninger W, Uthman A, Weich $\mathrm{H}$ and Tschachler E: Human keratinocytes express the three major splice forms of vascular endothelial growth factor. J Invest Dermatol 104: 7-10, 1995.

34. Wellmann S, Taube T, Paal K, Graf V, Einsiedel H, Geilen W, Seifert G, Eckert C, Henze G and Seeger K: Specific reverse transcription-PCR quantification of vascular endothelial growth factor (VEGF) splice variants by LightCycler technology. Clin Chem 47: 654-660, 2001.

35. Huez I, Bornes S, Bresson D, Creancier L and Prats H: New vascular endothelial growth factor isoform generated by internal ribosome entry site-driven CUG translation initiation. Mol Endocrinol 15: 2197-2210, 2001

36. Tee KM and Jaffe BJ: A precursor form of vascular endothelial growth factor arises by initiation from an upstream in-frame CUG codon. Biochem J 359: 219-226, 2001.

37. Bornes S, Boulard M, Hieblot C, Zanibellato C, Iacovoni JS, Prats $\mathrm{H}$ and Touriol C: Control of the vascular endothelial growth factor internal ribosome entry site (IRES) activity and translation initiation by alternative spliced coding sequences. J Biol Chem 279: 18717-18726, 2004

38. Potgens AJ, Lubsen NH, van Altena MC, Vermeulen R, Bakker A, Schoenmakers JG, Ruiter DJ and De Waal RM: Covalent dimerization of vascular permeability factor/vascular endothelial growth factor is essential for its biological activity. Evidence from Cys to Ser mutations. J Biol Chem 9: 32879-32885, 1994. 
39. Shibuya M, Yamaguchi S, Yamane A, Ikeda T, Tojo A, Matsushime $\mathrm{H}$ and Sato $\mathrm{M}$ : Nucleotide sequence and expression of a novel human receptor-type tyrosine kinase gene (flt) closely related to the fms family. Oncogene 5: 519-524, 1990.

40. Terman BI, Dougher-Vermazen M, Carrion ME, Dimitrov D, Armellino DC, Gospodarowicz D and Bohlen P: Identification of the KDR tyrosine kinase as a receptor for vascular endothelial cell growth factor. Biochem Biophys Res Commun 187: 1579-1586, 1992.

41. Pajusola K, Aprelikova O, Korhonen J, Kaipainen A, Pertovaara L, Alitalo R and Alitalo K: FLT4 receptor tyrosine kinase contains seven immunoglobulin-like loops and is expressed in multiple human tissues and cell lines. Cancer Res 52: 5738-5743, 1992.

42. Keyt BA, Nguyen HV, Berleau LT, Duarte CM, Park J, Chen H and Ferrara N: Identification of vascular endothelial growth factor determinants for binding KDR and FLT-1 receptors. Generation of receptor-selective VEGF variants by site-directed mutagenesis. J Biol Chem 271: 5638-5646, 1996.

43. Soker S, Takashima S, Miao HQ, Neufeld G and Klagsbrun M: Neuropilin-1 is expressed by endothelial and tumor cells as an isoform-specific receptor for vascular endothelial growth factor. Cell 92: 735-745, 1998.

44. Alon T, Hemo I, Itin A, Pe'er J, Stone J and Keshet E: Vascular endothelial growth factor acts as a survival factor for newly formed retinal vessels and has implications for retinopathy of prematurity. Nat Med 1: 1024-1028, 1995.

45. Ferrara N, Carver-Moore K, Chen H, Dowd M, Lu L, O'Shea KS Powell-Braxton L, Hillan KJ and Moore MW: Heterozygous embryonic lethality induced by targeted inactivation of the VEGF gene. Nature 380: 439-442, 1996.

46. Weidner N, Semple JP, Welch WR and Folkman J: Tumor angiogenesis and metastasis - correlation in invasive breast carcinoma. N Engl J Med 324: 1-8, 1991.

47. Fong GH, Rossant J, Gertsenstein M and Breitman ML: Role of the Flt-1 receptor tyrosine kinase in regulating the assembly of vascular endothelium. Nature 376: 66-70, 1995.

48. Volm M, Koomagi R and Mattern J: Interrelationships between microvessel density, expression of VEGF and resistance to doxorubicin of non-small lung cell carcinoma. Anticancer Res 16: 213-217, 1996 .

49. Detmar M, Yeo KT, Nagy JA, van de Water L, Brown LF, Berse B, Elicker BM, Ledbetter S and Dvorak HF: Keratinocytederived vascular permeability factor (vascular endothelial growth factor) is a potent mitogen for dermal microvascular endothelial cells. J Invest Dermatol 105: 44-50, 1995.

50. Detmar M, Brown LF, Schon MP, Elicker BM, Velasco P, Richard L, Fukumura D, Monsky W, Claffey KP and Jain RK: Increased microvascular density and enhanced leukocyte rolling and adhesion in the skin of VEGF transgenic mice. J Invest Dermatol 111: 1-6, 1998.

51. Xia YP, Li B, Hylton D, Detmar M, Yancopoulos GD and Rudge JS: Transgenic delivery of VEGF to mouse skin leads to an inflammatory condition resembling human psoriasis. Blood 102: 161-168, 2003

52. Kim I, Moon SO, Kim SH, Kim HJ, Koh YS and Koh GY: Vascular endothelial growth factor expression of intercellular adhesion molecule 1 (ICAM-1), vascular cell adhesion molecule 1 (VCAM-1), and E-selectin through nuclear factor-kappa B activation in endothelial cells. J Biol Chem 276: 7614-7620, 2001.

53. Lee TH, Avraham H, Lee SH and Avraham S: Vascular endothelial growth factor modulates neutrophil transendothelial migration via up-regulation of interleukin-8 in human brain microvascular endothelial cells. J Biol Chem 277: 10445-10451, 2002.

54. Barleon B, Sozzani S, Zhou D, Weich HA, Mantovani A and Marme D: Migration of human monocytes in response to vascular endothelial growth factor (VEGF) is mediated via the VEGF receptor flt-1. Blood 87: 3336-3343, 1996.

55. Clauss M, Weich H, Breier G, Knies U, Rockl W, Waltenberger J and Risau W: The vascular endothelial growth factor receptor Flt-1 mediates biological activities. Implications for a functional role of placenta growth factor in monocyte activation and chemotaxis. J Biol Chem 271: 17629-17634, 1996.

56. Oikawa T, Hirotani K, Ogasawara H, Katayama T, Nakamura O, Iwaguchi $\mathrm{T}$ and Hiragun A: Inhibition of angiogenesis by vitamin D3 analogues. Eur J Pharmacol 178: 247-250, 1990.
57. Diaz BV, Lenoir MC, Ladoux A, Frelin C, Demarchez M and Michel S: Regulation of vascular endothelial growth factor expression in human keratinocytes by retinoids. J Biol Chem 275: 642-650, 2000

58. Hernandez GL, Volpert OV, Iniguez MA, Lorenzo E, MartinezMartinez S, Grau R, Fresno M and Redondo JM: Selective inhibition of vascular endothelial growth factor-mediated angiogenesis by cyclosporin A: roles of the nuclear factor of activated T cells and cyclooxygenase 2. J Exp Med 193: 607-620, 2001.

59. Zumiani G, Zanoni M and Agostini G: Valutazione dell'efficacia dell'acqua della fonte termale di Comano versus acqua di acquedotto nella cura della psoriasi. G Ital Dermatol Venereol 135: 1-5, 2000.

60. Grice KA: Transepidermal water loss in pathological skin. In: Physiology and Pathophysiology of the Skin. Jarret A (ed). Academic Press, London, pp2147-2155, 1980.

61. Harding CR: The stratum corneum: structure and function in health and disease. Dermatol Ther 17 (Suppl 1): S6-S15, 2004.

62. Tsoureli-Nikita E, Menchini G, Ghersetich I and Hercogova J: Alternative treatment of psoriasis with balneotherapy using Leopoldine spa water. J Eur Acad Dermatol Venereol 16: 260-262, 2002.

63. Bradford MM: A rapid and sensitive method for the quantitation of microgram quantities of protein utilizing the principle of protein-dye binding. Anal Biochem 72: 248-254, 1976.

64. Shintani S, Li C, Ishikawa T, Mihara M, Nakashiro K and Hamakawa H: Expression of vascular endothelial growth factor A, B , C, and D in oral squamous cell carcinoma. Oral Oncol 40: $13-20,2004$.

65. Houck KA, Leung DW, Rowland AM, Winer J and Ferrara N: Dual regulation of vascular endothelial growth factor bioavailability by genetic and proteolytic mechanism. J Biol Chem 267: 26031-26037, 1992.

66. Yeo TK, Senger DR, Dvorak HF, Freter L and Yeo KT: Glycosylation is essential for efficient secretion but not for permeabilityenhancing activity of vascular permeability factor (vascular endothelial growth factor). Biochem Biophys Res Commun 179: 1568-1575, 1991 .

67. Zhang Y, Matsuo $\mathrm{H}$ and Morita E: Vascular endothelial growth factor 121 is the predominant isoform in psoriatic scales. Exp Dermatol 14: 758-764, 2005.

68. Muller YA, Christinger HW, Keyt BA and De Vos AM: The crystal structure of vascular endothelial growth factor (VEGF) refined to 1.93 A resolution: multiple copy flexibility and receptor binding. Structure 5: 1325-1338, 1997.

69. Park JE, Keller GA and Ferrara N: The vascular endothelial growth factor (VEGF) isoforms: differential deposition into the subepithelial extracellular matrix and bioactivity of extracellular matrix-bound VEGF. Mol Biol Cell 4: 1317-1326, 1993.

70. Cheng SY, Nagane M, Huang HS and Cavenee WK: Intracerebral tumor-associated hemorrhage caused by overexpression of the vascular endothelial growth factor isoforms VEGF121 and VEGF165 but not VEGF189. Proc Natl Acad Sci USA 94: 12081-12087, 1997.

71. Plouet J, Moro F, Bertagnolli S, Coldeboeuf N, Mazarguil H, Clamens S and Bayard F: Extracellular cleavage of the vascular endothelial growth factor 189-amino acid form by urokinase is required for its mitogenic effect. J Biol Chem 272: 13390-13396, 1997.

72. Ancelin M, Buteau-Lozano H, Meduti G, Osborne-Pellegrin M, Sordello S, Plouet J and Perrot-Applanat M: A dynamic shift of VEGF isoforms with a transient and selective progesteroneinduced expression of $\mathrm{VEGF}_{189}$ regulates angiogenesis and vascular permeability in human uterus. Proc Natl Acad Sci USA 99: 6023-6028, 2002.

73. Cohen T, Gitay-Goren H, Sharon R, Shibuya M, Halaban R, Levi BZ and Neufeld G: VEGF121, a vascular endothelial growth factor (VEGF) isoform lacking heparin binding ability, requires cell-surface heparan sulfates for efficient binding to the VEGF receptors of human melanoma cells. J Biol Chem 270: 11322-11326, 1995

74. Clauss MJ, Gerlach M, Gerlach H, Brett J, Wang F, Familletti PC, Pan YCE, Olander JV, Connoly DT and Stern D: Vascular permeability factor: a tumor-derived polypeptide that induces endothelial cell and monocyte procoagulant activity, and promotes monocyte migration J Exp Med 172: 1535-1545, 1990. 